\title{
Coronary artery bypass grafting versus percutaneous intervention in coronary revascularization: a historical perspective and review
}

\author{
This article was published in the following Dove Press journal: \\ Research Reports in Clinical Cardiology \\ 16 June 2015 \\ Number of times this article has been viewed
}

\author{
Sonya N Burgess' \\ John J Edmond ${ }^{2}$ \\ Craig $P$ Juergens 1 \\ John K French' \\ 'Department of Cardiology, Liverpool \\ Hospital and South Western Sydney \\ Clinical School, The University of \\ New South Wales, Sydney, NSW, \\ Australia; ${ }^{2}$ Department of Cardiology, \\ Dunedin Public Hospital, Dunedin, \\ New Zealand
}

Background: Coronary artery bypass graft surgery is arguably the most intensively studied surgical procedure, and percutaneous coronary intervention (PCI) has been subjected to more randomized clinical trials than any other interventional procedure. Changes seen in revascularization techniques have been numerous. The rapid evolution of evidence-based revascularization procedures has occurred as a result of many pivotal large randomized clinical trials.

Objective: This review compares and contrasts outcomes from two coronary revascularization techniques, coronary artery bypass grafting (CABG) and PCI, with particular reference to the landmark trials that inform practice guidelines.

Methods: We undertook a comprehensive review of published literature addressing trials in this field performed to address current knowledge both in the predrug-eluting stent and postdrug-eluting stent era.

Results and discussion: Surgical and percutaneous revascularization strategies have different strengths and weaknesses, and neither strategy is superior in all patients, clinical presentations, or anatomical subgroups. Current data support the use of percutaneous intervention in ST elevation myocardial infarction and in single-vessel disease. In noncomplex multivessel disease and isolated left main stem PCI, the data support non-inferiority of PCI compared to CABG as reflected in the 2014 European Society of Cardiology guidelines. Landmark revascularization trials of multivessel disease comparing $\mathrm{CABG}$ to $\mathrm{PCI}$ found no survival benefit to CABG over PCI, except in patients with complex disease. In these trials, revascularization drove differences in primary endpoints and in all but the patients with low Synergy Between Percutaneous Coronary Intervention with Taxus and Cardiac surgery score, rates of revascularization were significantly lower with CABG. The new 2014 European Society of Cardiology guidelines also reflect this. Conclusion: The field of coronary revascularization is complex and constantly evolving. The best revascularization strategy for an individual patient must take into account clinical presentation, comorbidities, the extent and complexity of the coronary artery disease, and data from trials reflecting contemporary practice.

Keywords: CABG, PCI, DES, SYNTAX, LMS, MACE, RCT

\section{Introduction and overview}

This review aims to compare and contrast outcomes from two coronary revascularization techniques, coronary artery bypass grafting (CABG) and percutaneous coronary intervention (PCI), with particular reference to the landmark trials that inform practice guidelines. Coronary revascularization was first performed in humans 70 years ago. ${ }^{1}$ Coronary artery bypass graft surgery is arguably the most intensively studied surgical
Correspondence: John K French Department of Cardiology, Liverpool Hospital, Elizabeth Street, Liverpool, NSW 2170, Australia

Tel +6I 298283069

Fax +6I 29828334 I

Email j.french@unsw.edu.au 
procedure, and PCI has been subjected to more randomized clinical trials than any other interventional procedure. ${ }^{2}$ Changes seen in revascularization techniques have been numerous, transforming both surgical and percutaneous procedures and outcomes. The rapid evolution of evidencebased revascularization procedures has occurred as a result of many pivotal large randomized clinical trials. While these trials have provided the evidence base to inform practice, reassessment is warranted as new techniques, devices, and adjunctive medications have subsequently been introduced. The evolution of coronary revascularization and landmark trials informing current practice are discussed.

This section discusses the evolution of surgical revascularization, and the evolution of percutaneous intervention. In the "Revascularization - guidelines" section, revascularization is reviewed in the context of major trials that have shaped contemporary evidence-based care. This section begins with an overview of current guidelines. Within this section, the evidence is first divided by anatomic subgroup: single-vessel disease, multivessel disease, and left main stem (LMS) disease. A section is also included on multivessel disease in patients with diabetes. The "STEMI and revascularization" section then reviews the impact of ST elevation myocardial infarction (STEMI) on decisions regarding revascularization, and discusses uncertainty in the current era regarding culprit vessel PCI vs complete revascularization. The importance of optimal medical therapy (OMT) and the heart team is also discussed. Finally, the impact of other patient comorbidities including severe left ventricular (LV) dysfunction and how these factors shape decisions regarding revascularization are discussed in the "Other considerations influencing outcomes and practice" section. Table 1 summarizes advantages and disadvantages of PCI and CABG.

\section{Evolution of surgical revascularization}

Surgery for coronary artery disease in humans was first performed in 1945. The Vineberg procedure, conceived by Arthur Vineberg, entailed direct implantation of the left internal mammary artery (LIMA) into the myocardium of the LV rather than providing a direct conduit to the major epicardial arteries. At this time, it was not believed that the diseased coronary artery was amenable to direct manipulation; therefore, the Vineberg LIMA implantation sought to take advantage of the myocardial sinusoids, and proposed that these sinusoidal spaces would behave as a sponge for LIMA run-off. ${ }^{3}$ Cardiopulmonary bypass was developed in $1954 .{ }^{4}$

Subsequently, Kolessov, in 1967, distally anastomosed the LIMA conduit to the left anterior descending
Table I Summary of advantages and disadvantages of $\mathrm{PCl}$ and $C A B G$

\begin{tabular}{|c|c|c|}
\hline & Advantages & Disadvantages \\
\hline \multirow[t]{3}{*}{$\mathrm{PCl}$} & Superior for acute (STEMI) patients & $\begin{array}{l}\text { Mandates dual } \\
\text { antiplatelet regimen }\end{array}$ \\
\hline & Short hospitalization & $\begin{array}{l}\text { Potentially incomplete } \\
\text { revascularization }\end{array}$ \\
\hline & $\begin{array}{l}\text { Early work resumption } \\
\text { Less invasive, and therefore suitable } \\
\text { for some comorbidities (eg, severe } \\
\text { pulmonary disease) }\end{array}$ & $\begin{array}{l}\text { Higher risk of } \\
\text { need for repeat } \\
\text { revascularization }\end{array}$ \\
\hline \multirow[t]{5}{*}{ CABG } & $\begin{array}{l}\text { Mortality benefit in diabetic patients } \\
\text { with MVD }\end{array}$ & More invasive \\
\hline & $\begin{array}{l}\text { Mortality benefit in complex } \\
\text { multivessel disease }\end{array}$ & $\begin{array}{l}\text { Higher risk of stroke } \\
\text { or neurological injury }\end{array}$ \\
\hline & More complete revascularization & Longer hospitalization \\
\hline & Lower risk of recurrent angina & $\begin{array}{l}\text { Requirement for } \\
\text { patent conduits }\end{array}$ \\
\hline & & $\begin{array}{l}\text { Wait times may limit } \\
\text { timely access in some } \\
\text { institutions and health } \\
\text { care settings }\end{array}$ \\
\hline
\end{tabular}

Abbreviations: $\mathrm{PCl}$, percutaneous coronary intervention; $\mathrm{CABG}$, coronary artery bypass grafting; STEMI, ST elevation myocardial infarction; MVD, multivessel disease.

artery (LAD). At this time, this technique was eclipsed by enthusiasm for saphenous venous grafting, developed by René Favaloro in 1968, which was technically less challenging. ${ }^{5,6}$ Data regarding saphenous graft failure were available in the $1970 \mathrm{~s},{ }^{7,8}$ with thrombosis and intimal and medial thickening challenging surgeons just as thrombosis and restenosis later challenged the interventionalist. Accelerated intimal hyperplasia, and premature atherosclerosis-limiting patency, was identified. Ten-year follow-up data from this era published in 1983 showed that $60 \%-70 \%$ of vein grafts were either occluded or severely stenosed. ${ }^{9,10}$

Radial arterial conduit use for CABG began in 1971; however, harvest techniques markedly different to contemporary techniques exposed the artery to trauma and spasm and resulted in high failure rates with significant intimal hyperplasia. Subsequently, the radial graft was abandoned by most surgeons until 1992 when Christopher Acar refined the no-touch technique for graft harvest, dramatically altering early patency results (Figure 1).,11

Superior late outcomes associated with internal mammary artery (IMA) grafts were noted in the early 1980s. ${ }^{12}$ Ten years after CABG, $90 \%-95 \%$ of LIMA grafts were patent and disease-free. ${ }^{13}$ Bilateral internal mammary artery (BIMA) graft use has been shown to further improve clinical outcome. In a small number of high-risk patients, BIMA use is complicated by sternal wound dehiscence. In spite of the studies led by Taggart et a $1^{14}$ supporting the 


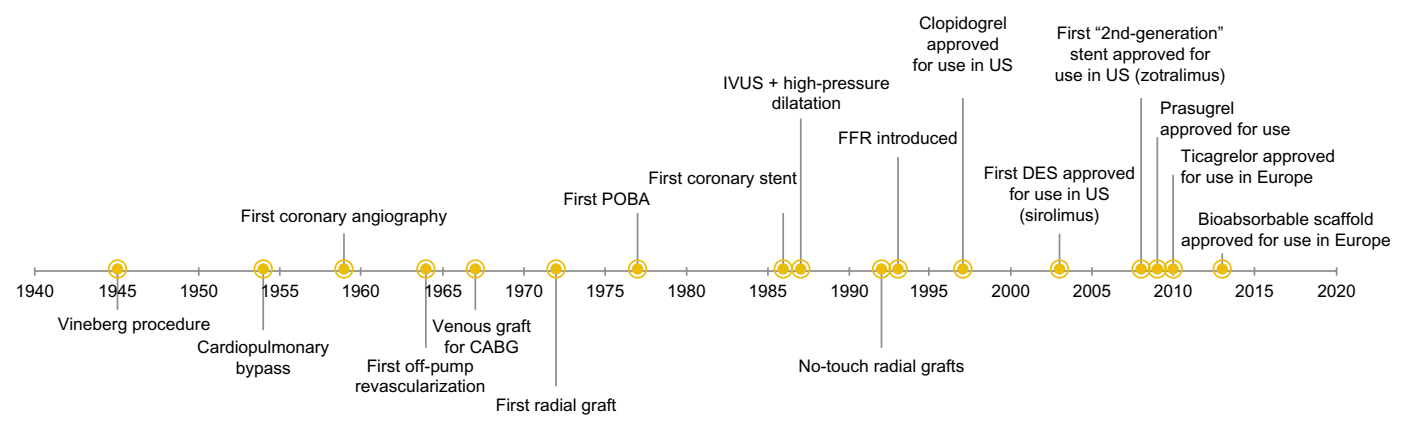

Figure I Coronary intervention timeline.

Abbreviations: CABG, coronary artery bypass grafting; POBA, balloon angioplasty alone; DES, drug-eluting stent; IVUS, intravascular ultrasound; FFR, fractional flow reserve.

use of BIMA, rates of routine practice remain as low as $5 \%-10 \% .^{14,15}$

Trials of off-pump surgery (also called beating heart surgery) began emerging in 2003. Off-pump surgery allows surgeons to perform bypass surgery without the use of a cardiopulmonary bypass machine. This technique was developed in an attempt to decrease morbidity associated with cardiopulmonary bypass, particularly neurocognitive deficits and stroke. However, concerns regarding long-term graft patency and increased need for revascularization with decreased long-term survival evident in several trials have decreased its use. ${ }^{16-21}$

Minimally Invasive Direct Coronary Artery Bypass Surgery (MIDCAB) also showed promise in the 1990s when first developed. This surgical technique uses a left anterior minithoracotomy and a beating heart technique to complete surgical bypass grafting, usually of the LAD, with the perceived advantages of a shorter hospital stay and a quicker recovery time. It is not suitable for multivessel disease and is also technically challenging, with concerns raised about the quality of the anastomosis using this technique. ${ }^{22-24}$ As a result, especially with the evolution of percutaneous techniques, MIDCAB is infrequently used. In addition, several techniques including the use of cardioplegia, preconditioning, improvements in postsurgical care, and various circulatory assistance devices have improved surgical outcomes.

\section{Evolution of percutaneous intervention}

Mason Sones performed the first selective coronary angiogram in 1958, and 19 years later, the first percutaneous balloon angioplasty was performed by Andreas Gruentzig. ${ }^{25}$ In the years that followed, the majority of revascularization was achieved surgically with CABG. Balloon angioplasty alone was complicated by high restenosis rates $(25 \%-40 \%)$ and acute vessel closure (3\%-5\%). In 1982, the first percutaneous transluminal coronary angioplasty was performed in the setting of acute myocardial infarction (MI) by Meyer et al. ${ }^{26}$
Sigwart et al implanted the first stents in human coronary arteries in $1986 .{ }^{27}$ When they were introduced, coronary stents were primarily used in the setting of acute and threatened closure after balloon angioplasty, and successfully reduced rates of these complications; however, restenosis and thrombosis rates were as high as $41 \%$ and $25 \%$, respectively, in early case series. ${ }^{28,29}$ Palmaz-Schatz stents were thought to be less thrombogenic initially, but a multicenter registry review found when aspirin and dypyridamole were used, rates were still high $(8 \%-16 \%)$. The use of warfarin was found to significantly reduce rates of subacute occlusion $(0.6 \%) .{ }^{30}$ In this era, bleeding and vascular complications associated with the escalation of anticoagulant regimens significantly limited the use of PCI. In 1995, the importance of high-pressure post-dilation was recognized, informed by the use of intracoronary ultrasound, and this optimization of stent deployment allowed the use of less aggressive anticoagulation with aspirin and ticlopidine (replacing warfarin and dypyridamole). ${ }^{31}$

A role for glycoprotein IIa/IIIb inhibitors (GPIs) was established in the 1990s, an era where routine stenting and thienopyridine-based dual antiplatelet therapy (DAPT) were not used. Pivotal trials in this era found a reduction in major cardiovascular events in stable and unstable patients undergoing PCI. ${ }^{32-35}$ However, as therapeutic options have evolved, the utility of GPI has become less clear in a variety of clinical settings, with major meta-analyses also producing conflicting results even in the setting of STEMI where their benefit was more evident. ${ }^{36-38}$

By the year 2000, more PCI procedures than CABG procedures were being performed in the US. ${ }^{39}$ In the same year, drug-eluting stents (DESs) were approved for use in both Europe and the US, with the first-in-man results, published in 2001, showing zero restenosis after DES implantation. ${ }^{40}$ Heralded as a safe, restenosis-proof, and easy-to-use stent, the introduction of DESs marked a time of great optimism in the interventional community. ${ }^{41}$ 
A growing body of evidence supported the value of primary percutaneous intervention in STEMI, a metaanalysis by Keeley et al, ${ }^{42}$ of trials comparing primary PCI to fibrinolysis published in 2003, enhanced the development of primary PCI programs.

Significant changes in DAPT strategies used with PCI were also facilitating safer PCI outcomes. The landmark Clopidogrel in Unstable angina to prevent Recurrent Events (CURE) trial ${ }^{43}$ was published in 2001, demonstrating a considerable benefit in treatment with clopidogrel in addition to aspirin, for 1 year, in patient treated with PCI.

By $2006,90 \%$ of PCIs were performed with DESs, and PCI procedures were almost five times more frequent than $\mathrm{CABG} .{ }^{39}$ However, in 2006, at the European Society of Cardiology (ESC) congress, significant concerns regarding late stent thrombosis with DAPT cessation were raised, ${ }^{44}$ which led to a short-term reduction in DES use. These events were rare, but associated with a high rate of death and MI. The late stent thrombosis was attributed to delayed or incomplete re-endothelialization secondary to the drug-induced inhibition of cell proliferation, and polymer-induced inflammation of the vessel wall. Second-generation stents eluting everolimus or zotarolimus (rather than sirolimus or paclitaxel) have since largely overcome concern regarding late stent thrombosis ${ }^{45-47}$ and were approved for use in the US in 2008. Second-generation DESs also use biocompatible, and in some cases, bioabsorbable polymers, and have improved stent strut design to reduce the risk of stent thrombosis and target vessel revascularization. It should be noted that most landmark trials comparing CABG to PCI enrolled patients before second-generation stents were available, and only two trials included any patients treated with second-generation DES. ${ }^{48,49}$ Indirect comparison using meta-analysis suggests potential equivalency between PCI with second-generation DES and CABG, but randomized controlled trials (RCTs) are not available. ${ }^{50}$

Further advances in pharmacology saw the introduction of prasugrel use in percutaneous intervention, following publication of the Trial to Assess Improvement in Therapeutic Outcomes by Optimizing Platelet Inhibition with Prasugrel (TRITON-TIMI 38) ${ }^{51}$ in 2007. Authors found an overall benefit with prasugrel vs clopidogrel use in the combined endpoint of death, MI, and cerebrovascular accident (CVA). In 2009, publication of the Study of Platelet Inhibition and Patient Outcomes (PLATO $^{52}$ demonstrated significant benefit in the combined endpoint, and notably, an overall mortality benefit, with ticagrelor treatment vs clopidogrel in acute coronary syndrome (ACS) patients. Whether the use of a reversible intravenous adenosine diphosphate-receptor antagonist such as cangrelor, which was shown in the Cangrelor vs Oral Clopidogrel for the Management of Periprocedural PCI Complications (CHAMPION PHOENIX) trial ${ }^{53}$ to improve 48-hour outcomes, will be widely accepted is yet to be determined.

Most recently, in 2013, the bioabsorbable scaffold was approved for use in Europe. This is a fully resorbable scaffold, which also promotes lumen enlargement and restoration of endothelial function, an innovation some authors are describing as the fourth revolution in interventional cardiology (Figure 1)..$^{54}$

\section{Revascularization - guidelines}

Surgical and percutaneous revascularization strategies have different strengths and weaknesses, and neither strategy is superior in all patients and all presentations. The American Heart Association and ESC provide guidelines directing evidence-based practice. Percutaneous intervention is recommended in STEMI and in single-vessel disease. The new ESC guidelines published in September $2014^{55}$ also recommend PCI for single-vessel proximal LAD as class IA, with PCI now assuming the same class as $\mathrm{CABG}$ treatment for singlevessel disease involving the proximal LAD. In noncomplex multivessel disease (those with a Synergy Between Percutaneous Coronary Intervention with Taxus and Cardiac surgery [SYNTAX] score of $\leq 22$ ) (see "Multivessel disease") and isolated LMS PCI (not involving the bifurcation), noninferiority has been suggested, but until recently, the current balance of evidence and guidelines favored surgical revascularization. However, the 2014 ESC guidelines now assign a IB recommendation for PCI in these settings, a recommendation equal to that assigned to $\mathrm{CABG}$ for simple LMS disease. The recommendation for $\mathrm{CABG}$, in three-vessel disease with a SYNTAX score of $\leq 22$, is now class IA..$^{55}$ In complex multivessel disease, particularly in patients with diabetes, surgical revascularization is recommended (class IA). 2,55,56 The new ESC guidelines also downgrade their recommendations for PCI in patients with complex three-vessel disease (SYNTAX $>22$ ) and complex left main (LM) disease (SYNTAX >33) to IIIB, that is, treatment not recommended and potentially harmful. The following subsections discuss landmark trials informing practice within different anatomical and patient subgroups.

\section{Revascularization trials - single-vessel disease}

Single-vessel disease coronary revascularization has been less comprehensively studied compared to multivessel revascularization. Predominantly, the research 
performed focuses on LAD disease, and little contemporary data can be found for single-vessel disease that does not involve the LAD. As a result, guidelines addressing treatment of the right coronary or circumflex territories are not primarily driven by level A or B evidence but come from consensus opinion, smaller studies, and meta-analysis. Single-vessel proximal LAD disease can be treated with either PCI or $\mathrm{CABG}$, and the new ESC guidelines published in September 2014 assign an equal class and level of evidence to both treatments (IA). ${ }^{55}$ Of the three publications primarily informing contemporary practice regarding single-vessel disease, two come from Thiele et al,,$^{57,58}$ the third is a meta-analysis from Kapoor et al in 2008..$^{59}$

In 2009, Thiele et al published a randomized single-center trial $(n=130)$ comparing first-generation sirolimus-eluting stents to CABG using the MIDCAB (see "The evolution of surgical revascularization") technique. Patients were recruited for this non-inferiority trial from 2003 to 2007 with all PCI patients receiving DAPT using clopidogrel with a $600 \mathrm{mg}$ loading dose and $75 \mathrm{mg}$ daily dose. The authors found PCI with a first-generation stent to be non-inferior to MIDCAB for isolated proximal LAD disease with respect to major adverse cardiac events (MACEs) at 12 months (their primary endpoint). Thiele et al found that non-inferiority was established individually for MI, at 12 months $(1.5 \%$ for PCI vs $7.7 \%$ for MIDCAB; non-inferiority, $P<0.001$ ), and no cardiac deaths were reported in either group; however, noninferiority was not established for the difference in revascularization ( $6.2 \%$ vs $0 \%$; non-inferiority, $P=0.21$ ). Periprocedural events were more frequent in the CABG group. Internal mammary arteries were used in $94 \%$ of cases. ${ }^{57}$

In 2013, Blazek et al also published a prospective randomized trial with 10-year follow-up of patients $(n=212)$ with isolated proximal LAD stenosis randomized to bare metal stent (BMS) PCI vs CABG (using MIDCAB). Patients were recruited and treated between 1997 and 2001. The primary endpoint was death, MI, and revascularization; they found no significant difference in the composite endpoint. Individually, there was no significant difference in death, cardiac death, or MI; the only significant differences were seen in target vessel revascularization ( $11 \%$ for CABG vs $34 \%$ for PCI; $P<0.001)$. All patients received IMA grafts in the CABG group, and notably in the PCI group, dual antiplatelet use was only for 4 weeks, and either ticlopidine or clopidogrel was used. Aspirin was recommended indefinitely for all PCI and $\mathrm{CABG}$ patients..$^{58}$

A meta-analysis by Kapoor et al published in 2008 addressing PCI vs CABG in patients with isolated disease of the proximal LAD studied publications from 1995 to 2005 (patients enrolled from 1989 to 2001). In this 19-year period, although 1,210 patients were included and nine RCTs assessed, applicability to contemporary practice is limited as only one of the nine RCTs used DESs (first generation). Balloon angioplasty alone was used for PCI in two of the eight remaining trials, and a third did not mandate stent use; rates of unstable angina varied significantly between trials and were as low as $8 \%$ in some groups. The Kapoor et al meta-analysis found no significant differences for mortality, and no difference in CVA or MI but disparity in revascularization, favoring $\mathrm{CABG}$; at 5 years, $7.3 \%$ of $\mathrm{CABG}$ patients vs $33.5 \%$ of $\mathrm{PCI}$ patients required revascularization. Arrhythmia, transfusion, and length of hospital stay were all significantly more frequent in $\mathrm{CABG}$ patients. ${ }^{59}$

In summary, available data on single-vessel disease are limited but appear to show differences driven only by revascularization in PCI vs CABG to the proximal LAD. Previous guidelines reflected this with a class I level $\mathrm{C}$ preference for PCI in single-vessel disease where the proximal LAD is not involved (vs class IIb, level C for CABG), which remains unchanged in the new guidelines. The alteration to note is that PCI for the proximal LAD was previously class IIa level B in 2010, whereas the 2014 guidelines now consider PCI and CABG equal assigning a class IA recommendation for both revascularization strategies. ${ }^{2,55}$

\section{Landmark revascularization trials Multivessel disease}

The majority of RCTs comparing CABG with PCI focus on multivessel disease. Landmark trials include the Bypass Angioplasty Revascularization Investigation (BARI) trial, ${ }^{60}$ the Arterial Revascularization Therapies (ARTS) randomized trial,${ }^{61}$ the Stent or Surgery (SoS) trial, ${ }^{62}$ the Medicine, Angioplasty, or Surgery Study (MASS II), ${ }^{63}$ the SYNTAX trial, ${ }^{64}$ the Coronary Artery Revascularisation in Diabetes (CARDia) trial, ${ }^{65}$ Veterans Affairs Coronary Artery Revascularization in Diabetes Study (VA CARDS), ${ }^{66}$ and the Future Revascularization Evaluation in Patients with Diabetes Mellitus: Optimal Management of Multivessel Disease (FREEDOM) trial. ${ }^{67}$ The first of these trials began in the balloon angioplasty era; only SYNTAX, CARDia, and FREEDOM include DES era data. Throughout these trials, more patients undergoing $\mathrm{CABG}$ receive complete or near complete revascularization, and complete revascularization in PCI patients was accomplished less often.

The first of these eight trials, the BARI, was published in 1996. This was a North American RCT of patients with 
multivessel coronary artery disease $(n=1,829)$. The BARI authors found no significant difference in survival at 10 years (CABG $73.5 \%$ vs PCI $71.0 \%$; $P=0.18$ ). There was no significant difference in 10-year survival free from $\mathrm{Q}$ wave $\mathrm{MI}$, but more frequent subsequent revascularization $(20.3 \%$ vs $76.8 \% ; P<0.001)$ in the PCI group. Major adverse cardiac and cerebrovascular events (MACCE) data were not provided. Patients were randomized between August 1988 and 1991. A total of $82 \%$ of CABG patients received an internal mammary graft. All initial angioplasty employed balloon angioplasty only. ${ }^{60,68}$

The ARTS trial was designed to compare both clinical outcomes and costs of available revascularization strategies, and was published in 2001 with 5-year outcomes published in 2005. This was a multicenter RCT $(n=1205)$ of patients with multivessel disease and was the first to compare BMSs with CABG. The ARTS authors found no significant difference in mortality at 5 years, and no significant difference was evident in the combined endpoint of death, stroke, or MI. Less frequent repeat revascularization occurred in the CABG group (8.8\% vs 30.3\%; $P<0.001$ ). Overall, MACCE (death, MI, revascularization, and CVA) were $21.8 \%$ for $C A B G$ patients and $41.7 \%$ for PCI $(P<0.001)$. Patients were randomized between April 1997 and June 1998. A total of 93\% of CABG patients received an internal mammary graft. Angioplasty employed BMS in $89 \%$ of cases, and balloon angioplasty only in the remaining treated lesions. ${ }^{61,69}$

The SoS trial was an international multicenter trial randomizing patients with multivessel disease to $\mathrm{CABG}$ or PCI with BMS ( $n=988)$. The SoS trial published 2-year data in 2002 and 6-year follow-up data in 2008. Patients were recruited from 1996 to 1999 . SoS authors found a survival advantage to $\mathrm{CABG}$ at 6 years $(6.8 \%$ vs $10.9 \% ; P=0.022)$. Interpretation of this data was confounded by an imbalance in the incidence of non-cardiovascular deaths due to cancer, eight in the CABG group and 20 in the PCI group, a pattern not seen in other trials. Although MI and revascularization rates at 6 years are not known, as 6-year follow-up included mortality only, at 2-year follow-up, there was no significant difference in survival free of $\mathrm{Q}$ wave $\mathrm{MI}$, but there was a significant difference in revascularization (6\% vs $21 \%$; $P<0.0001$ ) in favor of CABG, $\geq$ IMA was used in $93 \%$ of patients. ${ }^{62,70}$

The MASS II trial was first published in 2004, with 10 -year follow-up data published in 2010. This small singlecenter study $(n=611)$ enrolled patients with multivessel disease (MVD) and randomized 1:1:1 for CABG, PCI, and medical treatment only (MTO). The only RCT to include randomization to medical therapy only, this patient group was similar to the subsequently published Clinical Outcomes Utilizing Revascularization and Aggressive Drug Evaluation (COURAGE) trial $^{71}$ patients, as all patients had stable angina and preserved LV function. Patients were enrolled and treated from 1995 to 2000. Authors found no difference in survival at 10-year follow-up. There was a significant difference in nonfatal MI (10.3\% CABG vs 13.3\% PCI vs 20.7\% MTO at 10 -year follow-up; $P=0.004 *$ [CABG/PCI] and $P=0.008$ [CABG/MTO*]; ${ }^{*}$ Cox regression pairwise comparison) and more frequent subsequent revascularization $(7.4 \%$ CABG vs $41.9 \%$ PCI vs 39.4\% MTO; $P<0.001)$. Of CABG patients, $92 \%$ received internal mammary grafts. Angioplasty included balloon angioplasty, BMSs, lasers, and directional atherectomy. ${ }^{63,72}$

The SYNTAX trial was an "all-comers" international 85-center RCT enrolling patients with MVD and/or LMS disease (see "Landmark trials: LMS disease") $(n=1,800)$ comparing CABG to PCI. Patients were enrolled from 2005 until 2007. The SYNTAX score, a novel scoring system to predict outcomes based on coronary anatomic complexity, was used. Patients were categorized according to tertiles of SYNTAX score $1 \leq 22,23-32,>33$ ). The first results were published in 2009; 5-year follow-up data were published in 2013. Authors found that all-cause death and stroke were not significantly different. MI was significantly lower in the CABG group vs PCI $(3.8 \%$ vs $9.7 \% ; P<0.0001)$, and repeat revascularization occurred less $(13.7 \%$ vs $25.9 \% ; P<0.0001)$. MACCE rates were significantly different, $26.9 \%$ in CABG patients and $37.3 \%$ in PCI patients $(P>0.0001)$. Notably, this trial used heart team screening; DAPT was used with a thienopyridine for a minimum of 6 months, and a first-generation paclitaxeleluting stent was used in patients randomized to PCI. In the CABG group, $97.3 \%$ of patients had one or more arterial grafts. ${ }^{64,73}$

When dividing the SYNTAX score into low, intermediate, and high scores for lesion complexity/burden of disease, results differed. In those with a low SYNTAX score, no significant difference was seen for the primary endpoint (MACCE), nor were differences seen individually in all-cause death, cardiac death, stroke, MI, or repeat revascularization. ${ }^{73}$

In those with an intermediate SYNTAX score, significant differences were seen for MACCE (CABG 25.8\% vs PCI $36.0 \% ; P=0.008)$, MI (3.6\% vs $11.2 \% ; P=0.0009)$, and repeat revascularization $(12.7 \%$ vs $24.1 \% ; P=0.0005)$. No significant difference was evident when comparing allcause death, cardiac death, or stroke. ${ }^{73}$ 
In those with a high SYNTAX score, significant differences were seen in all categories except stroke. Patients with high SYNTAX score treated with CABG had lower MACCE rates $(26.8 \%$ vs $44.0 \% ; P<0.0001)$, all-cause death $(11.4 \%$ vs $19.2 \% ; P=0.005)$, cardiac death ( $4.9 \%$ vs $13.6 \% ; P=0.0002$ ), MI (3.9\% vs $10.1 \% ; P=0.004)$, and repeat revascularization $(12.1 \%$ vs $30.9 \% ; P<0.0001){ }^{73}$

The 2014 ESC guidelines recommend that CABG or PCI can be considered in three-vessel disease where the SYNTAX score is $\leq 22$ with greater strength of evidence for CABG (IA) vs PCI (IB). However, at SYNTAX scores $>22$, CABG is recommended (IA), and PCI is considered potentially harmful (IIIB). ${ }^{55}$

\section{Multivessel disease in patients with diabetes}

The BARI trial was the first randomized trial suggesting a mortality benefit for diabetic patients with CABG (vs PCI), a pattern not evident in nondiabetic patients. Subgroup analysis of diabetic patients in BARI was performed in response to a request from the data and safety monitoring board. In the 357 randomized subjects with medically treated diabetes, a significant difference was evident, with 5-year survival rates of $65.5 \%$ in the PCI group and $80.6 \%$ in the CABG group ( $P=0.003$ ); in the remaining $81 \%$ of the randomized BARI population, 5-year survival was described as essentially equal. ${ }^{68}$

The CARDia trial $(\mathrm{n}=510)$, a multicenter RCT from the UK, published in 2010, enrolled patients from 2002 to 2007. It was the first study to solely focus on revascularization in diabetic patients and included both multivessel and complex single-vessel LAD disease. Patients were treated with both
BMS $(n=70)$ and first-generation DESs $(n=178)$ as they became available. LIMA grafts were used in $94 \%$ of patients. Clopidogrel was used for only 1-3 months post-PCI with BMS and 12 months with DES; 95\% of patients received abciximab. Only $83.4 \%$ of patients were using aspirin at 1-year follow-up in the PCI group, compared with $87.2 \%$ of CABG patients $(P=0.258)$. The primary outcome was a combined endpoint of all-cause mortality, MI, and stroke at 1-year follow-up; non-inferiority was not demonstrated by the prespecified margin in the primary endpoint seen in $10.5 \%$ of CABG patients vs $13.0 \%$ in those treated with PCI at 1 year, $P=0.39$. There was no difference in all-cause mortality or MI. Repeat revascularization was significantly less common in the $\mathrm{CABG}$ group ( $2 \%$ vs $11.8 \% ; P<0.001)$. TIMI major bleeding was significantly higher in the $\mathrm{CABG}$ patients $6.1 \%$, than the PCI patients $1.2 \%(P=0.009)$. Nonfatal CVA rates were higher in the CABG patients $(2.8 \%$ vs $0.4 \% ; P=0.066)$. Authors acknowledged that CARDia was underpowered. ${ }^{65}$

Also underpowered was the VA CARDS,${ }^{66}$ which was a small study ( $\mathrm{n}=198)$ published within months of the larger FREEDOM trial. This multicenter randomized trial had significant problem with recruitment, screening 6,678 but including only $3 \%$ of those screened. The trial enrolled only $25 \%$ of the intended sample size, and patients were recruited from 2006 to 2010. Inclusion criteria were either isolated proximal LAD disease or LAD disease in the context of multivessel disease (as a result, only $46 \%$ of patients had a SYNTAX score higher than 22). DESs were used. Results must be viewed in terms of early termination and incomplete (25\%) recruitment. The primary endpoint, a combination

Table 2 Data for landmark multivessel trials comparing outcome

\begin{tabular}{|c|c|c|c|c|c|c|c|c|}
\hline Trial & $\begin{array}{l}\text { Publication } \\
\text { year } \\
\text { (final follow- } \\
\text { up year) }\end{array}$ & $\begin{array}{l}\text { Follow-up } \\
\text { (years) }\end{array}$ & PCI era & Death (\%) & MI (\%) & $\begin{array}{l}\text { Revascularization } \\
\text { (\%) }\end{array}$ & MACCE (\%) & CVA \\
\hline BARI $^{60,68}$ & 1996 (2006) & 10 & POBA only & NS & NS & 20.3 vs 76.8 & NA & NS \\
\hline ARTS 61,69 & 2001 (2005) & 5 & BMS & NS & NS & 8.8 vs 30.3 & 21.8 vs 41.7 & NS \\
\hline SoS ${ }^{62,70}$ & 2002 (2008) & $6^{a}$ & BMS & 6.8 vs 10.9 & NS & 6.0 vs 21 & NA & NS \\
\hline MASS $\|^{63,72}$ & $2004(2010)$ & 10 & BMS & NS & 10.3 vs 13.3 & 7.4 vs 41.9 & 33 vs $42.4^{b}$ & NS \\
\hline SYNTAX' 64,73 & $2009(2013)$ & 5 & DES & NS & 3.8 vs 9.7 & I 3.7 vs 25.9 & 26.9 vs 37.3 & NS \\
\hline Low & & & & NS & NS & NS & NS & NS \\
\hline Intermediate & & & & NS & 3.6 vs 11.2 & I 2.7 vs 24.1 & 25.8 vs 36.0 & NS \\
\hline High & & & & II.4 vs 19.2 & 3.9 vs 10.1 & 12.1 vs 30.9 & 26.8 vs 44.0 & NS \\
\hline
\end{tabular}

Notes: aSurvival data provided for 6-year follow-up. MI and revascularization data are available only for 2-year follow-up; ${ }^{b}$ combined endpoint in MASS did not include CVA data. For multiple follow-up times, latest published follow-up data are provided. All values represent CABG vs PCl respectively. Only statistically significant differences are listed, where $P>0.05$ NS is used.

Abbreviations: $\mathrm{PCl}$, percutaneous coronary intervention; MI, myocardial infarction; MACCE, major adverse cardiac and cerebrovascular events; CVA, cerebrovascular accident; BARI, Bypass Angioplasty Revascularization Investigation; POBA, balloon angioplasty alone; NS, nonsignificant; NA, not applicable/not provided by authors; ARTS, Arterial Revascularization Therapies; BMS, bare metal stent; SoS, Stent or Surgery; MASS II, Medicine, Angioplasty, or Surgery Study; SYNTAX, Synergy Between Percutaneous Coronary Intervention with Taxus and Cardiac surgery; DES, drug-eluting stent; CABG, coronary artery bypass grafting. 
of nonfatal MI and death, was not significantly different at 2 years. When viewed separately, mortality favored CABG ( $5 \%$ vs $21 \%$; hazard ratio [HR] 0.30; 95\% confidence interval [CI] 0.11-0.80), while nonfatal MI favored PCI (15\% vs $6.2 \%$; HR 3.32; 95\% CI 1.07-10.30). There was no significant difference in repeat revascularization at 2 years. The VA CARDS results were notably the only RCT results to show an increase in $\mathrm{MI}$ in CABG patients. The protocol mandated the use of serial electrocardiograms and nuclear studies in an attempt to detect symptomatically silent MIs; all of the silent MIs were found in the surgical arm, and represented $30 \%$ of all nonfatal MIs in CABG patients.

The FREEDOM trial is the largest of the landmark RCTs investigating revascularization of multivessel disease in patients with diabetes. Published in 2012, this 140-center RCT enrolled 1,900 patients from 2005 to 2010 (approximately $6 \%$ of those screened). The choice of DES (first or second generation) and surgical procedure was left to the discretion of the investigators. An average of 3.5 lesions were treated in the PCI group, and an average of 2.9 grafts were used in patients receiving $\mathrm{CABG}$. Of CABG patients, $95 \%$ received an IMA graft. The primary outcome, MACCE, was significantly lower with CABG at 5 years $(18.7 \%$ vs $26.6 \%$; $P=0.005)$, as was revascularization ( $2 \%$ vs $11.8 \% ; P<0.001)$, MI (6.0\% vs $13.9 \% ; P<0.001)$, and death $(10.9 \%$ vs $16.3 \%$; $P=0.049)$. Stroke was, however, more frequent in the CABG group $(5.2 \%$ vs $2.4 \% ; P=0.03) .{ }^{67}$

The FREEDOM trial supported the hypotheses, first generated from the subgroup analysis in BARI, that the differences in outcome in patients with multivessel disease treated with CABG vs PCI are significant in patients with diabetes and favor surgical revascularization. The FREEDOM cohort was substantially larger than the CARDia and VA CARDS cohorts, and FREEDOM patients had a higher burden of disease anatomically, as patients were required to have proximal disease in two or three major epicardial branches. Although all trials found some advantages for $\mathrm{CABG}$ over PCI in patients with diabetes, the benefit was more pronounced in the FREEDOM trial. The CARDia trial had a lower overall burden of coronary artery disease; the benefit seen in the CARDia trial was driven by revascularization, while there was no difference seen in death or MI. The benefit for revascularization in the FREEDOM trial was seen not only in repeat revascularization but also for MI and mortality.

The extent of coronary disease in FREEDOM participants was also quantified using the SYNTAX score. There was no interaction between the SYNTAX score and the effect of the two treatment strategies. It is possible that the trial was underpowered to analyze the interaction or reflects a lack of validity of the SYNTAX score in this patient population. It has also been noted that although overall the patients in FREEDOM had significantly better outcomes with CABG than with PCI, subgroup analysis reveals where the LAD was not involved (and therefore not grafted), 95\% CIs for hazard ratios are broad and more closely approach 1.0. Table 3 summarizes the data from landmark trials of patients with diabetes and multivessel disease.

In summary, landmark revascularization trials of multivessel disease comparing $\mathrm{CABG}$ to PCI found no survival benefit to $\mathrm{CABG}$ over PCI, except in patients with complex disease with a SYNTAX score of greater than 33 where there was a clear survival advantage with CABG. No difference was seen in rates of stroke. Rates of MI were generally not significantly different, except in the SYNTAX trial where a significant difference was seen in patients with a SYNTAX score greater than 22. Revascularization drove differences in primary endpoints where MACCE was the primary endpoint, and in all but the patients with low SYNTAX score, rates of revascularization were significantly lower with CABG. Table 2 summarizes the data from landmark trials of patients with multivessel disease.

In summary, in patients with diabetes and a high burden of disease, landmark trials have demonstrated a clear benefit to treatment with $\mathrm{CABG}$ (Table 3). Current guidelines reflect this and state that $\mathrm{CABG}$ should be considered rather than PCI where the extent of disease justifies a surgical approach and the patients risk profile is acceptable. The 2014 ESC guidelines have been upgraded to a class IA recommendation. ${ }^{2,55}$

\section{Landmark trials: LMS disease}

The management of significant LM stenosis has traditionally involved surgical revascularization. The reasons for this are twofold. The first is that data from the balloon angioplasty era showed high rates of elastic recoil and restenosis due to the relatively higher elastic tissue content within the aortic wall. ${ }^{74}$ The second is that disease may involve the bifurcation of the LAD and circumflex arteries, which often increases the complexity of the PCI strategy required. However, several RCTs suggest that LMS PCI in the DES era is much safer than originally anticipated.

The Unprotected Left Main Stenting Versus Bypass Surgery (LE MANS) study $(n=105)$, published in 2008, recruited patients from 2001 to 2004, and was the first prospective randomized trial comparing $\mathrm{PCI}$ and $\mathrm{CABG}$ in 
Table 3 Data for landmark multivessel trials in patients with diabetes comparing outcome

\begin{tabular}{lllllllll}
\hline Trial & $\begin{array}{l}\text { Publication } \\
\text { (years) }\end{array}$ & $\begin{array}{l}\text { Follow-up } \\
\text { (years) }\end{array}$ & PCI & Death (\%) & MI (\%) & Revascularization (\%) & MACCE (\%) & CVA \\
\hline CARDia $^{65}$ & 2010 & $\mathrm{I}$ & BMS and DES & NS & NS & 2 vs II.8 & 11.3 vs 19.3 & 2.8 vs 0.4 \\
VA CARDS $^{66}$ & 2013 & 2 & DES & 5 vs 21 & 15 vs $6.2^{\text {a }}$ & NS & NA & NS \\
FREEDOM $^{67}$ & 2012 & 5 & DES & 10.9 vs 16.3 & 6.0 vs 13.9 & 2.0 vs II & 18.7 vs 26.6 & 5.2 vs 2.4 \\
\hline
\end{tabular}

Notes: ${ }^{2}$ This trial was the only one to show more Mls in CABG patients. It is the only trial to mandate serial ECGs and nuclear studies in an attempt to detect symptomatically silent Ml; all of the silent Mls were found in the surgical arm, and represented $30 \%$ of nonfatal Mls in the surgical arm. All values represent CABG vs PCl.

Abbreviations: $\mathrm{PCl}$, percutaneous coronary intervention; MI, myocardial infarction; MACCE, major adverse cardiac and cerebrovascular events; CVA, cerebrovascular accident; CARDia, Coronary Artery Revascularisation in Diabetes; BMS, bare metal stent; DES, drug-eluting stent; NS, nonsignificant; VA CARDS, Veterans Affairs Coronary Artery Revascularization in Diabetes Study; NA, not applicable/not provided by authors; FREEDOM, Future Revascularization Evaluation in Patients with Diabetes Mellitus: Optimal Management of Multivessel Disease; CABG, coronary artery bypass grafting.

patients with unprotected LMS disease, where PCI employed both BMS (65\%) and DES (35\%). CR was achieved for $79 \%$ of PCI patients and $89 \%$ of CABG patients $(P=0.17)$. An arterial graft to the LAD was used in $81 \%$ of cases only, and only $72 \%$ of patients received an IMA graft. "T" stenting or "culotte" stenting was used in PCI to the LMS. The primary endpoint was LV ejection fraction (LVEF) at 1 year. Secondary endpoints were major adverse events (MAE) and MACCE. Patients treated with CABG did not have the increase in LVEF seen in those treated with PCI $(0.5 \% \pm 0.8 \%$ vs $3.3 \% \pm 6.7 \% ; P=0.047$ ), MAE was higher in $\mathrm{CABG}$ patients at 30 days $(28 \%$ vs $8 \% ; P<0.006)$, MACCE was higher at 30 days in $\mathrm{CABG}$ patients $(13 \%$ vs $2 \% ; P=0.03)$, and MACCE-free survival was comparable at 2 years. ${ }^{76}$ At 12 months, there were four deaths in the CABG group and one in the PCI group, three nonfatal MIs in the CABG group and one in the PCI group, and five repeat revascularizations in the CABG group vs 15 in the PCI group $(P=0.01) .{ }^{75}$

The Premier of Randomized Comparison of Bypass Surgery versus Angioplasty Using Sirolimus-Eluting Stent in Patients with Left Main Coronary Artery Disease (PRECOMBAT) trial $(\mathrm{n}=600)$, published in 2011, enrolled patients from 2004 to 2009 from 13 Korean sites, and randomized patients with unprotected LMS stenosis to CABG or PCI using first-generation sirolimus stents. PRECOMBAT authors found PCI to be non-inferior to CABG using a primary composite endpoint of MACCE, $6.7 \%$ for patients treated with $\mathrm{CABG}$ vs $8.7 \%$ for patients treated with PCI ( $95 \% \mathrm{CI}-1.6$ to $5.6 ; P=0.01$ for non-inferiority). Target vessel revascularization was lower in those treated with $\mathrm{CABG}$ (4.2\% vs $9.0 \% ; P=0.02$ ). The composite of death, MI, or stroke at 2 years was not significantly different. At 2 years, death rates were not significantly different, nor were rates of MI. Internal mammary grafting was performed in $93.6 \%$ of patients, and $63.8 \%$ of surgery was performed off pump. ${ }^{76}$

A smaller RCT from Boudriot et $\mathrm{al}^{77}(\mathrm{n}=201)$, published in 2011, enrolled patients from 2003 to 2009 from four
German tertiary centers. Patients with unprotected LM coronary artery disease were randomized to CABG or PCI with sirolimus-eluting stents and followed for 12 months. Boudriot et al found PCI to be inferior to CABG using a combined primary endpoint of MACCE including death, MI, and revascularization within 12 months; $\mathrm{CABG}$ patients had MACCE rates of $13.9 \%$ vs $19.0 \%$ ( $P=0.19$ for noninferiority). The rates of death, MI, or death and MI combined were not significantly different; the differences were driven by repeat revascularization $(5.9 \%$ vs $14.0 \% ; P=0.35$ for non-inferiority). Stroke was found to be higher in the CABG group ( $0 \%$ vs $2 \% ; P<0.001$ ). All but two of the stents used were sirolimus-eluting stents $4 \mathrm{~mm}$ in diameter or less; only two paclitaxel stents were employed where $4 \mathrm{~mm}$ stents were felt to be too small. Importantly, intravascular ultrasound use was not mandated. The site of stenosis was distal or at the bifurcation in $70 \%$ of CABG patients and $74 \%$ of $\mathrm{PCI}$ patients. Where a bifurcation was involved, provisional $\mathrm{T}$ stenting (54\%) and culotte stenting (41\%) were predominantly employed; crush stenting was used in $4 \%$ of cases, and kissing balloons mandated in all techniques. DAPT with a $600 \mathrm{mg}$ clopidogrel loading dose was also used. An LIMA was used in 99\% of cases and a RIMA in 54\%; radial arteries were used in $37 \%$; venous grafts in $35 \%$, and $46 \%$ used an off-pump technique. Average SYNTAX scores were 23.0 in CABG patients and 24.0 in PCI patients. ${ }^{77}$

The SYNTAX trial (described in the "Multivessel disease" section) provides the largest randomized dataset comparing $\mathrm{CABG}$ to $\mathrm{PCI}$ in patients with unprotected $\mathrm{LM}$ coronary artery disease $(n=705)$. Although the LM patients were a prespecified subgroup, and sufficiently powered for MACCE, as the primary endpoint of the overall SYNTAX trial did not meet criteria for non-inferiority, the data from this subgroup must be considered observational and hypothesis-generating only. Within the LM subgroup, at 5-year follow-up, there was no significant difference in MACCE. When dividing the baseline SYNTAX score into 
a low (0-22) or intermediate (22-33) score, there was no difference in cumulative event rate for MACCE; however, those with a SYNTAX score $\geq 33$ had MACCE rates favoring treatment with CABG $(29.7 \%$ vs $46.5 \% ; P=0.003)$. This was primarily due to repeat revascularization; at 1 year, those with low and intermediate SYNTAX scores had no significant difference in repeat revascularization in contrast to those with high scores where $4.8 \%$ of CABG patients vs $17.2 \%$ of PCI patients required repeat revascularization; $P<0.001$. One-year follow-up found no significant difference in any SYNTAX tertile for all-cause death, MI, or CVA. ${ }^{73,78}$ Table 4 summarizes the data from landmark trials of patients with LMS disease.

A meta-analysis $(n=14,203)$ published in 2013 by Athappan et al $^{79}$ assessing three randomized trials and 21 non-randomized trials also provides interesting data. It should be noted that five of the 21 non-randomized trials did not use propensity or multivariate adjustment of data, and the analysis excluded trials with less than 75\% DES use. Athappan et al found PCI to be a durable alternative to CABG over time with follow-up up to 5 years. At 5 -year follow-up, all-cause mortality was not significantly different, nor were MACCE. A statistically significant trend favoring CABG was seen for nonfatal MI (odds ratio [OR] 1.62; 95\% CI 1.05-2.50) and for subsequent revascularization differences that strongly favored CABG (OR 3.77; 95\% CI 2.43-5.87). However, CVA rates were significantly lower with PCI (OR 0.54; 95\% CI 0.31-0.94).

In summary, the best evidence from the last 6 years shows PCI treatment of isolated LMS lesions to be non-inferior to $\mathrm{CABG}$ treatment contrary to earlier recommendations. Advantages may include increased LVEF and decreased rates of CVA, but disadvantages include a higher rate of restenosis requiring subsequent revascularization. High-risk features such as those with concomitant MVD, anatomically unfavorable disease, and/or the presence of diabetes should be considered when selecting the mode of revascularization, as should the surgical risk and stability of the patient at the time of presentation. Guidelines have been changed to reflect this. The 2011 American College of Cardiology/American Heart Association guidelines upgraded LMS PCI from its former status as a class III indication in 2006 to a class IIb indication in 2009, to the current 2011 status of IIa where anatomy is favorable and surgical risk is high. ${ }^{56}$ ESC guidelines from 2010 recommended CABG for LM revascularization as the standard of care and that PCI for unprotected LM disease should only be considered in the absence of other revascularization options. ${ }^{2}$ The 2014 guidelines have altered significantly, recommending that simple LMS disease (SYNTAX score $<22$ ) now may be treated with PCI or CABG, with a IB recommendation for both. However, at higher SYNTAX scores, CABG is still preferred over PCI (IB vs IIaB) in LM with a SYNTAX score of 23-32, and strongly recommended where the SYNTAX score is $>32$ (IB vs IIIB), where it should be noted that $\mathrm{PCI}$ is not recommended and considered potentially harmful. ${ }^{55}$

\section{STEMI and revascularization}

In STEMI, often the immediate necessity of culprit artery reperfusion directs subsequent revascularization considerations in patients with multivessel disease. ${ }^{80}$ Guidelines suggest three settings where CABG in acute STEMI can be considered: the first, if the coronary anatomy is not amenable to PCI and the patient is in shock; the second, if the anatomy is unsuitable for PCI and the culprit artery is patent; and the third, where surgery is urgently required for repair of

Table 4 Data for landmark left main stem trials comparing outcome

\begin{tabular}{|c|c|c|c|c|c|c|c|c|}
\hline Trial & $\begin{array}{l}\text { Publication } \\
\text { year } \\
\text { (final follow- } \\
\text { up year) }\end{array}$ & $\begin{array}{l}\text { Follow-up } \\
\text { (years) }\end{array}$ & $\mathrm{PCl}$ & Death (\%) & MI (\%) & Revascularization (\%) & MACCE (\%) & CVA \\
\hline LE MANS 75 & 2008 & 2 & BMS and DES & NS & NS & 9.4 vs 28.8 & NS & NS \\
\hline PRECOMBAT $^{76}$ & 2011 & 2 & DES & NS & NS & 4.2 vs 9.0 & NS & NS \\
\hline Boudriot $^{77}$ & 2011 & 1 & DES & NS & NS & 5.9 vs 14.0 & 13.9 vs 19.0 & 2 vs 0 \\
\hline SYNTAX ${ }^{73,78}$ & $2009(2013)$ & 5 & DES & $N S^{a}$ & $N S^{a}$ & 6.7 vs $12.0^{\mathrm{a}}$ & $N S^{a}$ & 2.7 vs $0.3^{a}$ \\
\hline Low & & & & $\mathrm{NS}^{\mathrm{a}}$ & $N S^{a}$ & $N S^{a}$ & $N S^{b}$ & $N S^{a}$ \\
\hline Intermediate & & & & $\mathrm{NS}^{\mathrm{a}}$ & $\mathrm{NS}^{\mathrm{a}}$ & $N S^{a}$ & $N S^{b}$ & $\mathrm{NS}^{\mathrm{a}}$ \\
\hline High & & & & $\mathrm{NS}^{\mathrm{a}}$ & $N S^{a}$ & 4.8 vs $17.2^{\mathrm{a}}$ & 29.7 vs $46.5^{\mathrm{b}}$ & $N S^{a}$ \\
\hline
\end{tabular}

Notes: aData for SYNTAX trial primarily from I-year follow-up; bdata from 5-year follow-up. All values represent CABG vs PCI respectively.

Abbreviations: PCl, percutaneous coronary intervention; MI, myocardial infarction; MACCE, major adverse cardiac and cerebrovascular events; CVA, cerebrovascular accident; LE MANS, Unprotected Left Main Stenting Versus Bypass Surgery; BMS, bare metal stent; DES, drug-eluting stent; NS, nonsignificant; PRECOMBAT, Premier of Randomized Comparison of Bypass Surgery versus Angioplasty Using Sirolimus-Eluting Stent in Patients with Left Main Coronary Artery Disease; SYNTAX, Synergy Between Percutaneous Coronary Intervention with Taxus and Cardiac surgery; CABG, coronary artery bypass grafting. 
a mechanical complication. There are no RCTs to inform these decisions..$^{55,81}$

The best strategy for non-culprit disease in STEMI patients with multivessel disease post-primary PCI of the infarct-related artery is not well established, particularly in diabetic patients. Results from FREEDOM and the preventive angioplasty in acute myocardial infarction (PRAMI) trials ${ }^{82}$ (see "Completeness of revascularization") have led to much discussion and debate over the best practice for the treatment of the remaining multivessel disease, particularly in diabetic patients. Both the best mode of revascularization and the best timing for revascularization are unclear ${ }^{80}$ Deferred treatment of non-culprit vessels has to date been recommended, supported by class IIa level B evidence, ${ }^{81}$ and appropriate use criteria also support this approach. ${ }^{83}$ The results from PRAMI and the Complete versus Lesion only PRimary-PCI Trial (CVLPRIT), ${ }^{84}$ and the DANish study of optimal acute treatment of patients with ST-elevation Myocardial Infarction 3 (DANAMI-3; unpublished data), and Complete vs Lesiononly PRImary PCI Trial (COMPLETE), are likely to affect future guidelines.

Decisions made at the time of culprit PCI for STEMI may impact on the safety of future surgery, if surgery is required within a year of the index event. It is not clear whether modification of best practice for the index PCI is appropriate to facilitate safer early surgical revascularization if deemed appropriate, as it is likely that any benefits of surgery may be negated by such modifications, particularly if the LAD is the culprit vessel. It is also possible that in the setting of STEMI or recent PCI for STEMI, use of timely PCI for further revascularization rather delayed surgical revascularization (or inappropriate DAPT cessation to facilitate earlier surgery) is safer than surgical revascularization. Further research is required. Where evidence to answer these questions is incomplete, the use of a heart team approach becomes even more important. Current guidelines regarding revascularization post-STEMI state that the revascularization strategy should be based on the clinical status as well as the disease severity distribution and lesion characteristics, and involve the heart team approach (class I, level C). ${ }^{81}$

\section{Other considerations influencing outcomes and practice Completeness of revascularization}

One of the primary differences between CABG and PCI is the degree of revascularization provided. Trials do not consistently report the completeness of revascularization, and attempts to quantify completeness of revascularization are also limited by the lack of a universal definition. As a result, trials of CABG vs PCI rarely compare equivalent levels of complete revascularization. Surgical literature and practice have acknowledged the importance of complete revascularization for some time. In 1992, the coronary artery surgery study (CASS) authors noted better survival in $\mathrm{CABG}$ patients receiving three grafts vs one to two grafts. ${ }^{85}$ Observational studies since have yielded conflicting results regarding the importance of complete revascularization in PCI, although a recent large meta-analysis of 89,883 patients suggested a clear benefit. ${ }^{86}$ No large multicenter RCT has ever tested whether complete revascularization is superior to incomplete revascularization, although a subgroup analysis from the ARTS trial found a significant difference in MACE between patients with complete revascularization and incomplete revascularization. ${ }^{87}$ In the majority of trials discussed above, a significant disparity is seen in completeness of revascularization between CABG- and PCI-treated patients. It is possible that the differences between these groups reflect, at least in part, differences in the completeness of revascularization achieved rather than true differences in the method of revascularization. Further research is required on this topic.

\section{Optimal medical therapy}

When evaluating options for revascularization, other considerations must also be taken into account. While surgical and percutaneous revascularization have rapidly evolved transforming revascularization, pharmacological advances have been equally significant. OMT must be considered not simply as an adjunct to revascularization but also as an alternative.

The most often cited (and frequently miscited) COURAGE ${ }^{71,88}$ trial reminds Cardiologists of the importance of ensuring that patients are offered revascularization only when clinically indicated, particularly in patients without clearly demonstrable ischemia. COURAGE authors found that in patients with stable angina randomized to OMT or PCI, after an invasive coronary angiogram, at an average of 4.6 years of follow-up, no significant differences in the composite of death, MI, and stroke, and hospitalization for ACS or MI. Significant differences were seen in rates of subsequent revascularization favoring PCI $(21.1 \%$ in the PCI group vs $32.6 \%$ in OMT patients; $P<0.001)$ and in freedom from angina, until 5-year follow-up. A nuclear substudy of COURAGE found that PCI patients exhibited significant ischemia reduction ( $33 \%$ vs $19 \%$; $P=0.0004)$; this was particularly evident where patients had moderate-to-severe pretreatment ischemia; importantly, those with ischemia reduction had a lower unadjusted risk of death. ${ }^{71}$ 
The results from the Fractional Flow Reserve versus Angiography for Multivessel Evaluation 2 (FAME 2) ${ }^{89}$ further demonstrate the importance of inducible ischemia in defining those likely to benefit from revascularization. This RCT was stopped early when a clear benefit was seen with PCI treatment in patients with inducible ischemia (with a fractional flow reserve measurement of 0.80 or less), when compared with medical therapy alone. FAME 2 authors demonstrated a notable reduction in unplanned hospitalizations leading to urgent revascularization in patients randomized to $\mathrm{PCI}$ vs MTO (1.6\% vs $11.1 \%$; HR 0.13 ; 95\% CI $0.06-0.30 ; P<0.001$ ), and a significant reduction in the primary endpoint of death, MI, and urgent revascularization, with PCI: $4.3 \%$ and $12.7 \%$, respectively (HR 0.32; 95\% CI $0.19-0.53 ; P<0.001) .{ }^{89}$

\section{Heart team considerations}

Clinicians must also consider other coexisting indications for surgery and comorbidities affecting surgical risk. Evaluation of surgical risk is recommended before selecting the safest mode for revascularization, using a Euroscore or Society of Thoracic Surgeons (STS) score to stratify risk (class I level $\mathrm{B}$ recommendation), and in high-risk patients and where equipoise exists, use of the heart team is recommended. The heart team is usually a multidisciplinary team involving a noninvasive cardiologist, an invasive cardiologist, and a cardiac surgeon. ${ }^{2}$ Anatomic considerations must also be made, not simply to LMS disease or SYNTAX score as described above but also to distal or diffuse disease precluding effective surgical treatment, thereby potentially negating benefit. The importance of viability assessment must also be considered in both methods of revascularization, as revascularization of a scarred or nonviable territory exposes the patient to harm without the chance of benefit.

\section{Revascularization in severe LV dysfunction}

The management of ischemic cardiomyopathy with respect to the preferred method of revascularization is challenging, as there is a lack of strong data available to inform clinicians. Patients with severe LV dysfunction are often excluded from trials, ${ }^{63,69}$ or represent less than $2 \%$ of the study population. ${ }^{64,67}$ Available meta-analyses suggest no significant difference in overall mortality between CABG and PCI. ${ }^{90}$ Results from the Surgical Treatment for Ischemic Heart Failure (STICH) ${ }^{91}$ trial, which compared CABG and medical therapy to medical therapy alone, found no mortality benefit with surgery in all-cause mortality but did show lower rates of cardiac death and the combined endpoint of all-cause mortality and hospitalization. ESC guidelines recommend CABG in those with MVD or LMS disease and severe LVD (class I level B), but state that evidence for $\mathrm{PCI}$ is less established, and PCI in this setting has a class IIb, level $\mathrm{C}$ recommendation. ${ }^{2}$

\section{Conclusion}

The field of coronary revascularization is complex and constantly evolving. To make the best decisions for our patients, one needs to consider guidelines, new data, and technologies, and integrate this information into the care of individual patients, who may have their own preconceptions and comorbidities. Often, the data we have describe practices we have already replaced or improved upon. This is particularly the case when we depend on meta-analysis to adequately power clinically meaningful endpoints; interpretation in a changing world can be challenging.

Extrapolation of data is also potentially harmful. STEMI patients, for example, are often managed using principles of care developed for more stable ACS patients, as this group of patients are less likely to be enrolled in RCTs due to challenges of ethically appropriate informed consent in an emergency setting and those who are enrolled are likely to represent a more stable cohort. Trial data are needed to guide therapy.

Even in our most well-studied patient groups, such as patients with multivessel disease, where the differences between CABG and PCI have been comprehensively evaluated, it is uncertain whether the differences seen between $\mathrm{CABG}$ and PCI reflect innate differences between treatment modalities, or unequal levels of complete revascularization. In addition, comparative trials often do not extend to cover the lifetime of patients; in patients $<60$ years of age, PCI may be considered "surgery deferred" (with the exception of FREEDOM eligible patients), by avoiding late requirement for repeat $\mathrm{CABG}$ and its attendant increase in morbidity and mortality. However, protagonists of complete arterial revascularization contend that the use of BIMA grafting rarely requires subsequent repeat CABG. It should also be noted that most landmark trials compared CABG- to PCI-enrolled patients before secondgeneration stents were available, and only two trials, FREEDOM and VA CARDS, included any patients treated with second-generation DES.

Caveats aside, where the disease burden is high in multivessel disease, with a SYNTAX score greater than 22, or in diabetic patients with multivessel disease, and nonemergent presentation, current data strongly support CABG (with arterial grafts). Where urgent reperfusion is the issue, PCI is the preferred treatment. In single-vessel 
disease, PCI is also the revascularization strategy that is recommended.

The prognosis of patients with ischemic heart disease has been unrecognizably altered over the last 50 years. The research that has facilitated these changes and will inform future changes is critical, and the need for strong data to guide practice remains.

\section{Disclosure}

The authors report no conflicts of interest in this work.

\section{References}

1. Vineberg AM. Development of an anastomosis between the coronary vessels and a transplanted internal mammary artery. Can Med Assoc J. 1946;55(2):117-119.

2. Wijns W, Kolh P, Danchin N, et al; Task Force on Myocardial Revascularization of the European Society of Cardiology (ESC) and the European Association for Cardio-Thoracic Surgery (EACTS)1; European Association for Percutaneous Cardiovascular Interventions (EAPCI). Guidelines on myocardial revascularization. Eur Heart $J$. 2010;31(20):2501-2555.

3. Tsang JC, Chiu RC. The phantom of "myocardial sinusoids": a historical reappraisal. Ann Thorac Surg. 1995;60(6):1831-1835.

4. Buxton BF, Galvin SD. The history of arterial revascularization: from Kolesov to Tector and beyond. Ann Cardiothorac Surg. 2013;2(4): 419-426.

5. Favaloro RG. Saphenous vein autograft replacement of severe segmental coronary artery occlusion: operative technique. Ann Thorac Surg. 1968;5(4):334-339.

6. Kolessov VI. Mammary artery-coronary artery anastomosis as method of treatment for angina pectoris. JThorac Cardiovasc Surg. 1967;54(4): 535-544.

7. Grondin CM. Aortocoronary bypass grafts. Arch Surg. 1971; 103(5):535.

8. Lawrie GM, Lie JT, Morris GC, Beazley HL. Vein graft patency and intimal proliferation after aortocoronary bypass: early and long-term angiopathologic correlations. Am J Cardiol. 1976;38(7):856-862.

9. Lytle BW, Loop FD, Cosgrove DM, Ratliff NB, Easley K, Taylor PC. Long-term ( 5 to 12 years) serial studies of internal mammary artery and saphenous vein coronary bypass grafts. J Thorac Cardiovasc Surg. $1985 ; 89(2): 248-258$.

10. Campeau L, Enjalbert M, Lespérance J, Vaislic C, Grondin CM, Bourassa MG. Atherosclerosis and late closure of aortocoronary saphenous vein grafts: sequential angiographic studies at 2 weeks, 1 year, 5 to 7 years, and 10 to 12 years after surgery. Circulation. 1983; 68(3 pt 2):II1-II7.

11. Acar C, Jebara VA, Portoghese M, et al. Revival of the radial artery for coronary artery bypass grafting. Ann Thorac Surg. 1992;54(4): 652-659.

12. Loop FD, Lytle BW, Cosgrove DM, et al. Influence of the internalmammary-artery graft on 10-year survival and other cardiac events. N Engl J Med. 1986;314(1):1-6.

13. Fitzgibbon GM, Kafka HP, Leach AJ, Keon WJ, Hooper GD, Burton JR. Coronary bypass graft fate and patient outcome: angiographic followup of 5,065 grafts related to survival and reoperation in 1,388 patients during 25 years. J Am Coll Cardiol. 1996;28(3):616-626.

14. Taggart DP, Altman DG, Gray AM, et al; ART Investigators. Randomized trial to compare bilateral vs single internal mammary coronary artery bypass grafting: 1-year results of the arterial revascularisation trial (ART). Eur Heart J. 2010;31(20):2470-2481.

15. Taggart DP. Does a hybrid approach to multivessel revascularisation really make sense? EuroIntervention. 2013;8(11):1231-1233.
16. Sellke FW, DiMaio JM, Caplan LR, et al. Comparing on-pump and off-pump coronary artery bypass grafting: numerous studies but few conclusions: a scientific statement from the American heart association council on cardiovascular surgery and anesthesia in collaboration with the interdisciplinary working group on quality of care and outcomes research. Circulation. 2005;111(21):2858-2864.

17. Puskas JD, Williams WH, Mahoney EM, et al. Off-pump vs conventional coronary artery bypass grafting: early and 1-year graft patency, cost, and quality-of-life outcomes: a randomized trial. JAMA. 2004;291(15):1841-1849.

18. Nathoe HM, van Dijk D, Jansen EW, et al; Octopus Study Group. A comparison of on-pump and off-pump coronary bypass surgery in low-risk patients. N Engl J Med. 2003;348(5):394-402.

19. Légaré JF, Buth KJ, King S, et al. Coronary bypass surgery performed off pump does not result in lower in-hospital morbidity than coronary artery bypass grafting performed on pump. Circulation. 2004;109(7): 887-892.

20. Widimsky P, Straka Z, Stros P, et al. One-year coronary bypass graft patency: a randomized comparison between off-pump and on-pump surgery angiographic results of the PRAGUE-4 trial. Circulation. 2004;110(22):3418-3423.

21. Shroyer AL, Grover FL, Hattler B, et al; Veterans Affairs Randomized On/Off Bypass (ROOBY) Study Group. On-pump versus off-pump coronary-artery bypass surgery. $N$ Engl J Med. 2009;361(19):1827-1837.

22. Mehran R, Dangas G, Stamou SC, et al. One-year clinical outcome after minimally invasive direct coronary artery bypass. Circulation. 2000;102(23):2799-2802.

23. Katz WE, Zenati M, Mandarino WA, Cohen HA, Gorcsan J. Assessment of left internal mammary artery graft patency and flow reserve after minimally invasive direct coronary artery bypass. Am J Cardiol. 1999;84(7):795-801.

24. Diegeler A, Matin M, Kayser S, et al. Angiographic results after minimally invasive coronary bypass grafting using the minimally invasive direct coronary bypass grafting (MIDCAB) approach. Eur $J$ Cardiothorac Surg. 1999;15(5):680-684.

25. Meier B. The first patient to undergo coronary angioplasty -23 -year follow-up. N Engl J Med. 2001;344(2):144-145.

26. Meyer J, Merx W, Schmitz H, et al. Percutaneous transluminal coronary angioplasty immediately after intracoronary streptolysis of transmural myocardial infarction. Circulation. 1982;66(5):905-913.

27. Sigwart U, Puel J, Mirkovitch V, Joffre F, Kappenberger L. Intravascular stents to prevent occlusion and restenosis after transluminal angioplasty. N Engl J Med. 1987;316(12):701-706.

28. Roubin GS, Cannon AD, Agrawal SK, et al. Intracoronary stenting for acute and threatened closure complicating percutaneous transluminal coronary angioplasty. Circulation. 1992;85(3):916-927.

29. Serruys PW, Strauss BH, Beatt KJ, et al. Angiographic follow-up after placement of a self-expanding coronary-artery stent. $N$ Engl J Med. 1991;324(1):13-17.

30. Schatz RA, Baim DS, Leon M, et al. Clinical experience with the Palmaz-Schatz coronary stent. Initial results of a multicenter study. Circulation. 1991;83(1):148-161.

31. Colombo A, Hall P, Nakamura S, et al. Intracoronary stenting without anticoagulation accomplished with intravascular ultrasound guidance. Circulation. 1995;91(6):1676-1688.

32. The EPIC Investigators. Use of a monoclonal antibody directed against the platelet glycoprotein IIb/IIIa receptor in high-risk coronary angioplasty. The EPIC Investigation. $N$ Engl J Med. 1994;330(14): 956-961.

33. EPILOG Investigators. Platelet glycoprotein IIb/IIIa receptor blockade and low-dose heparin during percutaneous coronary revascularization. N Engl J Med. 1997;336(24):1689-1696.

34. EPISTENT Investigators. Randomised placebo-controlled and balloon-angioplasty-controlled trial to assess safety of coronary stenting with use of platelet glycoprotein-IIb/IIIa blockade. Lancet. 1998;352(9122):87-92. 
35. [No authors listed] Effects of platelet glycoprotein IIb/IIIa blockade with tirofiban on adverse cardiac events in patients with unstable angina or acute myocardial infarction undergoing coronary angioplasty. The RESTORE investigators. Randomized efficacy study of tirofiban. Circulation. 1997;96(5):1445-1453.

36. Hanna EB, Rao SV, Manoukian SV, Saucedo JF. The evolving role of glycoprotein IIb/IIIa inhibitors in the setting of percutaneous coronary intervention strategies to minimize bleeding risk and optimize outcomes. JACC Cardiovasc Interv. 2010;3(12):1209-1219.

37. Dippel EJ, Kereiakes DJ, Tramuta DA, et al. Coronary perforation during percutaneous coronary intervention in the era of abciximab platelet glycoprotein IIb/IIIa blockade: an algorithm for percutaneous management. Catheter Cardiovasc Interv. 2001;52(3):279-286.

38. Geeganage C, Wilcox R, Bath PMW. Triple antiplatelet therapy for preventing vascular events: a systematic review and meta-analysis. BMC Med. 2010;8:36.

39. Lange RA, Hillis LD. Coronary revascularization in context. $N$ Engl J Med. 2009;360(10):1024-1026.

40. Sousa JE, Costa MA, Abizaid A, et al. Lack of neointimal proliferation after implantation of sirolimus-coated stents in human coronary arteries: a quantitative coronary angiography and three-dimensional intravascular ultrasound study. Circulation. 2001;103(2):192-195.

41. Lemos PA, Serruys PW, Sousa JE. Drug-eluting stents: cost versus clinical benefit. Circulation. 2003;107(24):3003-3007.

42. Keeley EC, Boura JA, Grines CL. Primary angioplasty versus intravenous thrombolytic therapy for acute myocardial infarction: a quantitative review of 23 randomised trials. Lancet. 2003;361(9351): $13-20$.

43. Mehta SR, Yusuf S, Peters RJ, et al; Clopidogrel in Unstable angina to prevent Recurrent Events trial (CURE) Investigators. Effects of pretreatment with clopidogrel and aspirin followed by long-term therapy in patients undergoing percutaneous coronary intervention: the PCI-CURE study. Lancet. 2001;358(9281):527-533.

44. Joner M, Finn AV, Farb A, et al. Pathology of drug-eluting stents in humans: delayed healing and late thrombotic risk. J Am Coll Cardiol. 2006;48(1):193-202.

45. Bangalore S, Kumar S, Fusaro M, et al. Short- and long-term outcomes with drug-eluting and bare-metal coronary stents: a mixed-treatment comparison analysis of 117762 patient-years of follow-up from randomized trials. Circulation. 2012;125(23):2873-2891.

46. Palmerini T, Biondi-Zoccai G, Della Riva D, et al. Stent thrombosis with drug-eluting and bare-metal stents: evidence from a comprehensive network meta-analysis. Lancet. 2012;379(9824):1393-1402.

47. Sarno G, Lagerqvist B, Fröbert O, et al. Lower risk of stent thrombosis and restenosis with unrestricted use of "new-generation" drug-eluting stents: a report from the nationwide Swedish coronary angiography and angioplasty registry (SCAAR). Eur Heart J. 2012;33(5): 606-613.

48. Kamalesh M, Sharp TG, Tang XC, et al; VA CARDS Investigators. Percutaneous coronary intervention versus coronary bypass surgery in United States veterans with diabetes. J Am Coll Cardiol. 2013;61(8): $808-816$.

49. Farkouh ME, Dangas G, Leon MB, et al. Design of the future revascularization evaluation in patients with diabetes mellitus: optimal management of multivessel disease (FREEDOM) Trial. Am Heart $J$. 2008;155(2):215-223.

50. Bangalore S, Toklu B, Feit F. Outcomes with coronary artery bypass graft surgery versus percutaneous coronary intervention for patients with diabetes mellitus: can newer generation drug-eluting stents bridge the gap? Circ Cardiovasc Interv. 2014;7(4):518-525.

51. Wiviott SD, Braunwald E, McCabe $\mathrm{CH}$, et al; TRITON-TIMI 38 Investigators. Prasugrel versus clopidogrel in patients with acute coronary syndromes. $N$ Engl J Med. 2007;357(20):2001-2015.

52. Wallentin L, Becker RC, Budaj A, et al; PLATO Investigators. Ticagrelor versus clopidogrel in patients with acute coronary syndromes. $N$ Engl J Med. 2009;361(11):1045-1057.
53. Bhatt DL, Stone GW, Mahaffey KW, et al. Effect of platelet inhibition with cangrelor during PCI on ischemic events. $N$ Engl $J$ Med. 2013;368(14):1303-1313. doi:10.1056/NEJMoa1300815.

54. Onuma Y, Serruys PW. Bioresorbable scaffold: the advent of a new era in percutaneous coronary and peripheral revascularization? Circulation. 2011;123(7):779-797.

55. Windecker S, Kolh P, Alfonso F, et al. 2014 ESC/EACTS guidelines on myocardial revascularization: the task force on myocardial revascularization of the European Society of Cardiology (ESC) and the European Association for Cardio-Thoracic Surgery (EACTS) * developed with the special contribution of the European Association of Percutaneous Cardiovascular Interventions (EAPCI). Eur Heart $J$. 2014;35:2541-2619.

56. Levine GN, Bates ER, Blankenship JC, et al. 2011 ACCF/AHA/ SCAI Guideline for percutaneous coronary intervention: a report of the American College of Cardiology Foundation/American Heart Association task force on practice guidelines and the society for cardiovascular angiography and interventions. Circulation. 2011;124(23): e574-e651.

57. Thiele H, Neumann-Schniedewind P, Jacobs S, et al. Randomized comparison of minimally invasive direct coronary artery bypass surgery versus sirolimus-eluting stenting in isolated proximal left anterior descending coronary artery stenosis. J Am Coll Cardiol. 2009;53(25): 2324-2331.

58. Blazek S, Holzhey D, Jungert C, et al. Comparison of bare-metal stenting with minimally invasive bypass surgery for stenosis of the left anterior descending coronary artery: 10-year follow-up of a randomized trial. JACC Cardiovasc Interv. 2013;6(1):20-26.

59. Kapoor JR, Gienger AL, Ardehali R, et al. Isolated disease of the proximal left anterior descending artery comparing the effectiveness of percutaneous coronary interventions and coronary artery bypass surgery. JACC Cardiovasc Interv. 2008;1(5):483-491.

60. Alderman EL, Andrews K, Bost J. Comparison of coronary bypass surgery with angioplasty in patients with multivessel disease. The bypass angioplasty revascularization investigation (BARI) investigators. N Engl J Med. 1996;335(4):217-225.

61. Serruys PW, Unger F, Sousa JE, et al; Arterial Revascularization Therapies Study Group. Comparison of coronary-artery bypass surgery and stenting for the treatment of multivessel disease. $N$ Engl J Med. 2001;344(15):1117-1124.

62. SoS Investigators. Coronary artery bypass surgery versus percutaneous coronary intervention with stent implantation in patients with multivessel coronary artery disease (the Stent or Surgery trial): a randomised controlled trial. Lancet. 2002;360(9338):965-970.

63. Hueb W, Soares PR, Gersh BJ, et al. The medicine, angioplasty, or surgery study (MASS-II): a randomized, controlled clinical trial of three therapeutic strategies for multivessel coronary artery disease: one-year results. J Am Coll Cardiol. 2004;43(10):1743-1751.

64. Serruys PW, Morice MC, Kappetein AP, et al; SYNTAX Investigators. Percutaneous coronary intervention versus coronary-artery bypass grafting for severe coronary artery disease. $N$ Engl J Med. 2009;360(10): 961-972.

65. Kapur A, Hall RJ, Malik IS, et al. Randomized comparison of percutaneous coronary intervention with coronary artery bypass grafting in diabetic patients. 1-year results of the CARDia (coronary artery revascularization in diabetes) trial. $J$ Am Coll Cardiol. 2010;55(5): 432-440.

66. Kamalesh M, Sharp TG, Tang XC, et al; VA CARDS Investigators. Percutaneous coronary intervention versus coronary bypass surgery in United States veterans with diabetes. J Am Coll Cardiol. 2013;61(8): 808-816.

67. Farkouh ME, Domanski M, Sleeper LA, et al. Strategies for multivessel revascularization in patients with diabetes. $N$ Engl $J$ Med. 2012;367(25):2375-2384

68. BARI Investigators. The final 10-year follow-up results from the BARI randomized trial. J Am Coll Cardiol. 2007;49(15):1600-1606. 
69. Serruys PW, Ong AT, van Herwerden LA, et al. Five-year outcomes after coronary stenting versus bypass surgery for the treatment of multivessel disease: the final analysis of the arterial revascularization therapies study (ARTS) randomized trial. J Am Coll Cardiol. 2005;46(4):575-581.

70. Booth J, Clayton T, Pepper J, et al; SoS Investigators. Randomized, controlled trial of coronary artery bypass surgery versus percutaneous coronary intervention in patients with multivessel coronary artery disease: six-year follow-up from the stent or surgery trial (SoS). Circulation. 2008;118(4):381-388.

71. Shaw LJ, Berman DS, Maron DJ, et al. Optimal medical therapy with or without percutaneous coronary intervention to reduce ischemic burden: results from the clinical outcomes utilizing revascularization and aggressive drug evaluation (COURAGE) trial nuclear substudy. Circulation. 2008;117(10):1283-1291.

72. Hueb W, Lopes N, Gersh BJ, et al. Ten-year follow-up survival of the medicine, angioplasty, or surgery study (MASS II): a randomized controlled clinical trial of 3 therapeutic strategies for multivessel coronary artery disease. Circulation. 2010;122(10):949-957.

73. Mohr FW, Morice MC, Kappetein AP, et al. Coronary artery bypass graft surgery versus percutaneous coronary intervention in patients with three-vessel disease and left main coronary disease: 5-year follow-up of the randomised, clinical SYNTAX trial. Lancet. 2013;381(9867):629-638.

74. Serruys PW, Onuma Y, Garg S, et al; ARTS II Investigators. 5-year clinical outcomes of the ARTS II (arterial revascularization therapies study II) of the sirolimus-eluting stent in the treatment of patients with multivessel de novo coronary artery lesions. J Am Coll Cardiol. 2010;55(11):1093-1101.

75. Buszman PE, Kiesz SR, Bochenek A, et al. Acute and late outcomes of unprotected left main stenting in comparison with surgical revascularization. J Am Coll Cardiol. 2008;51(5):538-545.

76. Park SJ, Kim YH, Park DW, et al. Randomized trial of stents versus bypass surgery for left main coronary artery disease. $N$ Engl J Med. 2011;364(18):1718-1727.

77. Boudriot E, Thiele H, Walther T, et al. Randomized comparison of percutaneous coronary intervention with sirolimus-eluting stents versus coronary artery bypass grafting in unprotected left main stem stenosis. J Am Coll Cardiol. 2011;57(5):538-545.

78. Morice MC, Serruys PW, Kappetein AP, et al. Outcomes in patients with de novo left main disease treated with either percutaneous coronary intervention using paclitaxel-eluting stents or coronary artery bypass graft treatment in the Synergy Between Percutaneous Coronary Intervention with TAXUS and Cardiac Surgery (SYNTAX) trial. Circulation. 2010;121(24):2645-2653.

79. Athappan G, Patvardhan E, Tuzcu ME, Ellis S, Whitlow P, Kapadia SR. Left main coronary artery stenosis: a meta-analysis of drug-eluting stents versus coronary artery bypass grafting. JACC Cardiovasc Interv. 2013;6(12):1219-1230.
80. Burgess SN, Mussap CJ, French JK. Management of acute coronary syndromes in patients with diabetes: implications of the FREEDOM trial. Clin Ther. 2013;35(8):1069-1075.

81. Steg PG, James SK, Atar D, et al; Task Force on the management of ST-segment elevation acute myocardial infarction of the (ESC). ESC Guidelines for the management of acute myocardial infarction in patients presenting with ST-segment elevation. Eur Heart J. 2012; 33(20):2569-2619.

82. Wald DS, Morris JK, Wald NJ, et al; PRAMI Investigators. Randomized trial of preventive angioplasty in myocardial infarction. $N$ Engl J Med. 2013;369(12):1115-1123.

83. Patel MR, Dehmer GJ, Hirshfeld JW, et al; Coronary Revascularization Writing. ACCF/SCAI/STS/AATS/AHA/ASNC/HFSA/SCCT 2012 appropriate use criteria for coronary revascularization focused update: a report of the American College of Cardiology Foundation Appropriate Use Criteria Task Force, Society for Cardiovascular Angiography and Interventions, Society of Thoracic Surgeons, American Association for Thoracic Surgery, American Heart Association, American Society of Nuclear Cardiology, and the Society of Cardiovascular Computed Tomography. J Am Coll Cardiol. 2012;59(9):857-881.

84. Gershlick AH, Khan JN, Kelly DJ, et al. Randomized Trial of Complete Versus Lesion-Only Revascularization in Patients Undergoing Primary Percutaneous Coronary Intervention for STEMI and Multivessel Disease. J Am Coll Cardiol. 2015;65(10):963-972.

85. Coronary artery surgery study (CASS): a randomized trial of coronary artery bypass surgery. Survival data. Circulation. 1983;68(5): 939-950.

86. Garcia S, Sandoval Y, Roukoz H, et al. Outcomes after complete versus incomplete revascularization of patients with multivessel coronary artery disease: a meta-analysis of 89,883 patients enrolled in randomized clinical trials and observational studies. J Am Coll Cardiol. 2013;62(16): 1421-1431.

87. van den Brand MJ, Rensing BJ, Morel MA, et al. The effect of completeness of revascularization on event-free survival at one year in the ARTS trial. J Am Coll Cardiol. 2002;39(4):559-564.

88. Boden WE, O'Rourke RA, Teo KK, et al; COURAGE Trial Research Group. Optimal medical therapy with or without PCI for stable coronary disease. N Engl J Med. 2007;356(15):1503-1516.

89. De Bruyne B, Pijls NH, Kalesan B, et al; FAME 2 Trial Investigators. Fractional flow reserve-guided PCI versus medical therapy in stable coronary disease. N Engl J Med. 2012;367(11):991-1001.

90. Kunadian V, Pugh A, Zaman AG, Qiu W. Percutaneous coronary intervention among patients with left ventricular systolic dysfunction: a review and meta-analysis of 19 clinical studies. Coron Artery Dis. 2012;23(7):469-479.

91. Velazquez EJ, Williams JB, Yow E, et al. Long-term survival of patients with ischemic cardiomyopathy treated by coronary artery bypass grafting versus medical therapy. Ann Thorac Surg. 2012;93(2):523-530.
Research Reports in Clinical Cardiology

\section{Publish your work in this journal}

Research Reports in Clinical Cardiology is an international, peerreviewed, open access journal publishing original research, reports, editorials, reviews and commentaries on all areas of cardiology in the clinic and laboratory. The manuscript management system is completely online and includes a very quick and fair peer-review system.

\section{Dovepress}

Visit http://www.dovepress.com/testimonials.php to read real quotes from published authors. 